\title{
Three-Dimensional Trajectory Design for Reducing Climate Impact of Trans-Atlantic Flights
}

\author{
Hok K. $\mathrm{Ng}^{1}$ \\ University of California, Santa Cruz, Moffett Field, CA 94035-1000 \\ Banavar Sridhar ${ }^{2}$, Neil Y. Chen ${ }^{3}$ \\ NASA Ames Research Center, Moffett Field, CA 94035-1000 \\ Jinhua $\mathrm{Li}^{4}$ \\ Stinger Ghaffarian Technologies, Moffett Field, CA 94035-1000
}

\begin{abstract}
The impact of aircraft emissions and contrails on the environment adds an additional aspect to aircraft trajectory optimization. This study developed a three-dimensional trajectory optimization algorithm for trans-Atlantic flights in cruise to generate aircraft trajectories that minimize environmental impacts due to $\mathrm{CO}_{2}$ emissions and contrails in the presence of winds. The climate-optimal trajectory is developed using dynamic programming that adjusts a wind-optimal aircraft heading while determining the optimal locations, altitudes and times for en-route step climbs. Flying wind-optimal routes minimize aircraft travel time, fuel burn and associated emissions during cruise while adjusting aircraft heading and en-route step climbs at the optimal locations and times minimize climate impact of contrails. This capability integrates an air traffic management simulation with aircraft fuel burn and emissions models, contrail formation and dispersion models, simplified climate response models, and a common climate metric. A study was conducted to evaluate the potential cost and benefits of flying climate-optimal routes in North Atlantic Airspace and their impacts to the Organized Track System design based on the trans-Atlantic air traffic during a day, July 12, 2012. Results show eastbound flights achieved a larger environmental benefit with less additional fuel burn than westbound flights that operated in strong headwinds that caused more additional fuel burn and aircraft emissions to avoid traversing contrails favorable regions.
\end{abstract}

\section{Introduction}

A viation is responsible for $2 \%$ of all anthropogenic $\mathrm{CO}_{2}$ emissions ${ }^{1}$ in which a large portion takes place at altitudes where the emissions remain longer than if emitted at the surface. Another source of aircraft induced climate impact comes from persietent contrails that may cause more climate warming today than all the residual $\mathrm{CO}_{2}$ emitted by aircraft ${ }^{2}$. The climate impact of $\mathrm{CO}_{2}$ emissions and contrails can be estimated in terms of "radiative forcing" (RF) which is positive and has an approximately linear relationship with global mean surface temperature change. $\mathrm{CO}_{2}$ has a long-term effect on temperature change while contrails have a short-term effect that varies by geographical location, altitude and time of the formation. Aircraft trajectories that are designed for mitigating the impact of $\mathrm{CO}_{2}$ emission and contrails on climate change require an integration of aircraft emissions models, contrail formation and dispersion models, climate response models and a common metric for assessing their climate effects within the same time horizon and a practical trajectory optimization approach for a national-level airspace simulation and optimization.

Previous operational strategies in air traffic management such as adjusting cruise altitude ${ }^{3-4}$, rerouting aircraft horizontal path ${ }^{5}$ or a combination of both ${ }^{5-6}$ were studied for mitigating the impact of persistent contrails on climate change. Those strategies were developed without the use of a common metric to evaluate the climate effect of

\footnotetext{
${ }^{1}$ Research Scientist, U.C. Santa Cruz, MS 210-8, Member AIAA.

${ }^{2}$ Senior Scientist for Air Transportation Systems, Aviation Systems Division, Fellow.

${ }^{3}$ Aerospace Research Engineer, Systems Modeling and Optimization Branch, MS 210-10, Member AIAA.

${ }^{4}$ Researcher, Stinger Ghaffarian Technologies, Inc.
} 
aircraft emissions and contrails. To fill that gap, a commonly used climate metric ${ }^{7}$ such as Global Warming Potential (GWP) and Absolute Global Temperature Potential (AGTP) was used as a common scale to compare various impacts from different greenhouse gases. Several authors ${ }^{8-9}$ have used that common metric and linear climate models to assess the impact of aviation on climate. A recent study ${ }^{10}$ modeled the climate response to aviation emissions and contrails as outputs from a series of linear dynamic systems and assesed the effect in terms of AGTP. The model was integrated with a national-level air traffic simulation and optimization capability for studying the trade-off of environmental impact between $\mathrm{CO}_{2}$ emission and contrails. The integrated system assumed the climate impacts are independent of the location of aircraft emissions and contrail formation. Locations of airspace favorable to persistent contrail formation were modeled as regions to be avoided by aircraft by imposing a soft penalty for going through these regions. For those studies, simplying assumptions about contrail coverage were made. Contrails were assumed to be uniform inside the penalty regions without considering the size of contrail area and its lifetime. The horzontal maneuvers of aircraft trajectories were optimized using objective cost functions that approximately penalize contrail formation ${ }^{5,10}$.

This study extends previous work ${ }^{4,5,10}$ by developing a new three-dimensional trajectory optimization algorithm for trans-Atlantic flights in cruise to generate climate-optimal aircraft trajectories in winds that minimize aviationinduced global temperature change due to $\mathrm{CO}_{2}$ emissions and contrails. This study also uses a newer climate model has also been improved to include contrail diffusion and advection which improve the assessment of climate impact due to contrails formed and induced at a given location and altitude. The climate-optimal trajectory is developed by adjusting wind-optimal aircraft sequential heading changes while determining the optimal locations, altitudes and times for en-route step climbs based on the concept of dynamic programming. This optimization algotithm is integrated with aircraft fuel burn and emission models, contrail formation and trasportation models, simplified climate response models and a climate metric with an air traffic management simulation. The climate-optimal routes aimed at minimizing the short, medium and long term aviation induced climate impacts are compared to the windoptimal routes in North Atlantic oceanic airspace in for differeneces in travel time, fuel burn, AGTP reduction, and variation of route structure.

Section II describes the models for assessing the potential climate impact of $\mathrm{CO}_{2}$ emissions and contrails in terms of AGTP. Section III explains the three-dimensional climate-optimal trajectory generation. Section IV describes climate-optimal trajectories generated for trans-Atlantic flights and compares them to the wind-optimal trajectories. Conclusions and future work are described in Section V.

\section{Linear Climate Models}

This section describes the climate response model based on linear dynamic systems that uses aircraft $\mathrm{CO}_{2}$ emission and contrails. The climate response model for aircraft $\mathrm{CO}_{2}$ emission is adopted from a previous study. ${ }^{10}$ That recent study ${ }^{11}$ assessed the climate impact of contrails that depended on the formation location through simulating the dynamic evolution of contrails triggered by cruising aircraft based on Lagrangian particle dispersion model and cloud microphysics model. This study applies the contrail formation and evolution model to assess the climate response to contrail formed at different locations in the airspace. Section IIA introduces AGTP as the climate metric used in this study for assessing aviation-induced global warming. Section IIB and IIC models AGTP due to $\mathrm{CO}_{2}$ emission and contrails, respectively.

\section{A. Absolute Global Temperature Change Potential}

Absolute Global Temperature Change Potential (AGTP) ${ }^{12}$ is a climate assessment metric that adapts a linear system for modeling the global temperature response to aviation emissions and contrails. The definition of the absolute GTP is a convolution integral from $t_{0}=0$ to $t=H$, and has the following representation,

$$
\operatorname{AGTP}(H)=\int_{0}^{H} R(H-\zeta) \Delta F(\zeta) d \zeta
$$

where $R(H-\xi)$ is the impulse response function for the surface temperature change at time $H$ due to radiative forcing $\Delta F(\xi)$ applied at $\zeta$. Note that temperature change $\Delta T\left(t, t_{0}\right)$ on the Earth surface is equivalent to the $\operatorname{AGTP}(H)$ when a simplified climate model is chosen. Two versions of AGTP are available in the literature. The pulse AGTP measures the change in the global temperature at a particular time, $t$, in the future due to an instantaneous disruption at $t_{0}$. The sustained AGTP measures the global temperature change at time $t$ due to disruptions constantly applied for a period between $t$ and $t_{0}$. 
The pulse AGTP is employed in this study for translating aviation induced $\mathrm{CO}_{2}$ emissions and persistent contrails into total effect on global warming. The formulations for AGTP due to $\mathrm{CO}_{2}$ emission and contrails are provided in the following subsections.

\section{B. Pulse AGTP for $\mathrm{CO}_{2}$ emission}

The impact of $\mathrm{CO}_{2}$ on climate is better understood than the impact of all other greenhouse gases and contrails. The carbon cycle models describe the changes to the $\mathrm{CO}_{2}$ concentration due to the transport and absorption of $\mathrm{CO}_{2}$ by the land mass and various ocean layers. The change in RF for $\mathrm{CO}_{2}$ emissions, $\Delta F^{\mathrm{CO}_{2}}$, is made of a steady-state component and three exponentially decaying components with a specific forcing, $A^{\mathrm{CO}_{2}}=1.82 \times 10^{-15} \mathrm{Wm}^{-2} / \mathrm{kg} \mathrm{of} \mathrm{CO}_{2}$, a value taken from past studies ${ }^{13}$. The temperature response/energy balance to RF, $R(H-\zeta)$ can be modeled using either a first order linear model ${ }^{14}$ or a second order linear model ${ }^{15}$. The pulse AGTP for $1 \mathrm{~kg} \mathrm{CO}_{2}$ emission for a time horizon $H$ can then be found based on Eq. (1) by applying a second order model for the impulse response function, $R(t)$, taken from the literature. ${ }^{7}$

Table 1 shows the pulse AGTP values per kilogram of $\mathrm{CO}_{2}$ emission for three time horizons. The absolute global temperature potentials are expressed in terms of the specific forcing, $\mathrm{A}^{\mathrm{CO}_{2}}$, since different values can be selected from the literature.

Table 1. Absolute global temperature potential values for $\mathrm{CO}_{2}$ emission.

\begin{tabular}{|c|c|c|c|}
\hline Horizon (years) & $\mathrm{H}=25$ & $\mathrm{H}=50$ & $\mathrm{H}=100$ \\
\hline $\begin{array}{c}\text { Pulse } A G T P^{\mathrm{CO}_{2}}(H) \\
(\mathrm{K} / \mathrm{kg})\end{array}$ & $A^{\mathrm{CO}_{2}} \times 0.3686$ & $A^{\mathrm{CO}_{2}} \times 0.3176$ & $A^{\mathrm{CO}_{2}} \times 0.2788$ \\
\hline
\end{tabular}

\section{Pulse AGTP for Persistent Contrails}

The surface temperature response for contrails is modeled similarly. An impulse function best characterizes radiative forcing due to contrails since contrails usually last for several hours in the atmosphere. The pulse AGTP for contrails formation is simply taken as the impulse response. For a unit of contrails induced radiative forcing, the pulse AGTP is represented by

$$
\operatorname{AGTP}^{\text {Contrails }}(H)=\int_{0}^{H} R(H-\zeta) \delta(\zeta-0) d \zeta=R(H) .
$$

Equation (2) computes surface temperature change to a unit of energy induced to the atmosphere by contrails. The net radiative forcing for contrails includes the longwave $R F_{L W}$ and the shortwave $R F_{S W}$ radiative forcing and is defined as $R F_{\text {nets }}=R F_{L W}+R F_{S W}$. It is measured in terms of unit of power (Watts) per unit area of contrails $\left(\mathrm{m}^{2}\right)$. Typical values for $R F_{\text {nets }}$ have a range between $10 \mathrm{~W} / \mathrm{m}^{2}$ and $30 \mathrm{~W} / \mathrm{m}^{2}$ taken from Meerkötter ${ }^{16}$ and Haywood ${ }^{17}$. Due to the nature of contrail formation, it is argued that it is better to represent contrail radiative forcing in terms of unit distance flown by the aircraft (watts $/ \mathrm{km}$ ). The amount of energy, $E F$, induced to the atmosphere for a unit length of contrail over its lifetime is defined as ${ }^{18}$

$$
E F=\int_{\text {lifetime }} R F_{\text {nets }}(\zeta) W_{c}(\zeta) d \zeta
$$

where $W_{c}$ is contrail width (m). Suppose $R F_{\text {nets }}=10 \mathrm{~W} / \mathrm{m}^{2}$, contrail width $W=1,000 \mathrm{~m}$ and contrail lifetime is $10,000 \mathrm{~s}$, the energy $E F$ for a km contrail equals 100 Gigajoules (GJ).

In general, contrail width varies over time and contrail lifetime depends on the atmospheric conditions at where the contrails formed. The contrail dispersion due to turbulent mixing is modeled using a diffusion equation. The energy $E F$ per km contrail can be formulated using Eq. (3) given $R F_{\text {nets }}$ and the time-varying contrail width.

The global surface temperature change, $\operatorname{AGTP}^{\text {Contrails }}(H)$, is then computed by multiplying Eq. (2) by the energy after it is normalized by the surface area of the Earth and total seconds in a year. Suppose the diffusion coefficients in the horizontal direction is $20 \mathrm{~m}^{2} / \mathrm{s}$, the initial contrail width is $80 \mathrm{~m}$, and $R F_{\text {nets }}=10 \mathrm{~W} / \mathrm{m}^{2}$, the contrail width, the energy force, and the pulse AGTP values for 3 time horizons at the end of each hour for the first ten hours are 
computed are shown in Table 2 . Note that the pulse AGTP values can be linearly scaled when other $R F_{\text {nets }}$ values are chosen. The lifetime of contrail depends on the actual atmospheric conditions and dispersion.

Table 2. Contrail width, radiative forcing, and pulse AGTP for different lifetimes.

\begin{tabular}{|l|l|l|l|l|l|l|l|l|l|l|}
\hline Lifetime (hr) & 1 & 2 & 3 & 4 & 5 & 6 & 7 & 8 & 9 & 10 \\
\hline Width $(\mathrm{m})$ & 388 & 543 & 662 & 763 & 852 & 933 & 1007 & 1076 & 1141 & 1203 \\
\hline EF (GJ) & 12 & 32 & 56 & 84 & 116 & 151 & 189 & 229 & 272 & 317 \\
\hline $\begin{array}{l}\text { Pulse AGTP(25) } \\
\left(1 \times 10^{-14} \mathrm{~K} / \mathrm{km}\right)\end{array}$ & 0.359 & 0.944 & 1.68 & 2.53 & 3.48 & 4.52 & 5.65 & 6.86 & 8.14 & 9.48 \\
\hline $\begin{array}{l}\text { Pulse AGTP(50) } \\
\left(1 \times 10^{-14} \mathrm{~K} / \mathrm{km}\right)\end{array}$ & 0.084 & 0.220 & 0.391 & 0.589 & 0.811 & 1.06 & 1.32 & 1.60 & 1.90 & 2.21 \\
\hline $\begin{array}{l}\text { Pulse } A G T P(100) \\
\left(1 \times 10^{-14} \mathrm{~K} / \mathrm{km}\right)\end{array}$ & 0.061 & 0.161 & 0.286 & 0.431 & 0.593 & 0.771 & 0.964 & 1.17 & 1.39 & 1.62 \\
\hline
\end{tabular}

Figure 1 shows the AGTP values potentially induced by persistent contrail formation across the North Atlantic oceanic airspace at 6 a.m. EDT on July 12, 2012. The colored polygons depict the potential contrail formation areas at 36,000 feet above sea level. The various colors represent the AGTP values for a 25 year horizon contributed per kilometer of contrail formation at the corresponding location when $\mathrm{RF}_{\text {net }}$ is $10 \mathrm{~W} / \mathrm{m}^{2}$. The contrail formation and computation of aircraft trajectories use forecasts of wind, humidity and temperature provided by the Global Forecast System (GFS). GFS is a global numerical weather prediction computer model run by the National Oceanic \& Atmospheric Administration four times a day. It produces forecasts up to 16 days, and produces a forecast for every $3^{\text {rd }}$ hour for the first 180 hours, and after that, every 12 hours. The horizontal resolution is roughly equivalent to $0.5 \times 0.5$ degree latitude/longitude. GFS data has 64 unequally-spaced vertical isobaric pressure levels ranging between $0.25-1000 \mathrm{mb}$, with enhanced resolution at low and high altitude.

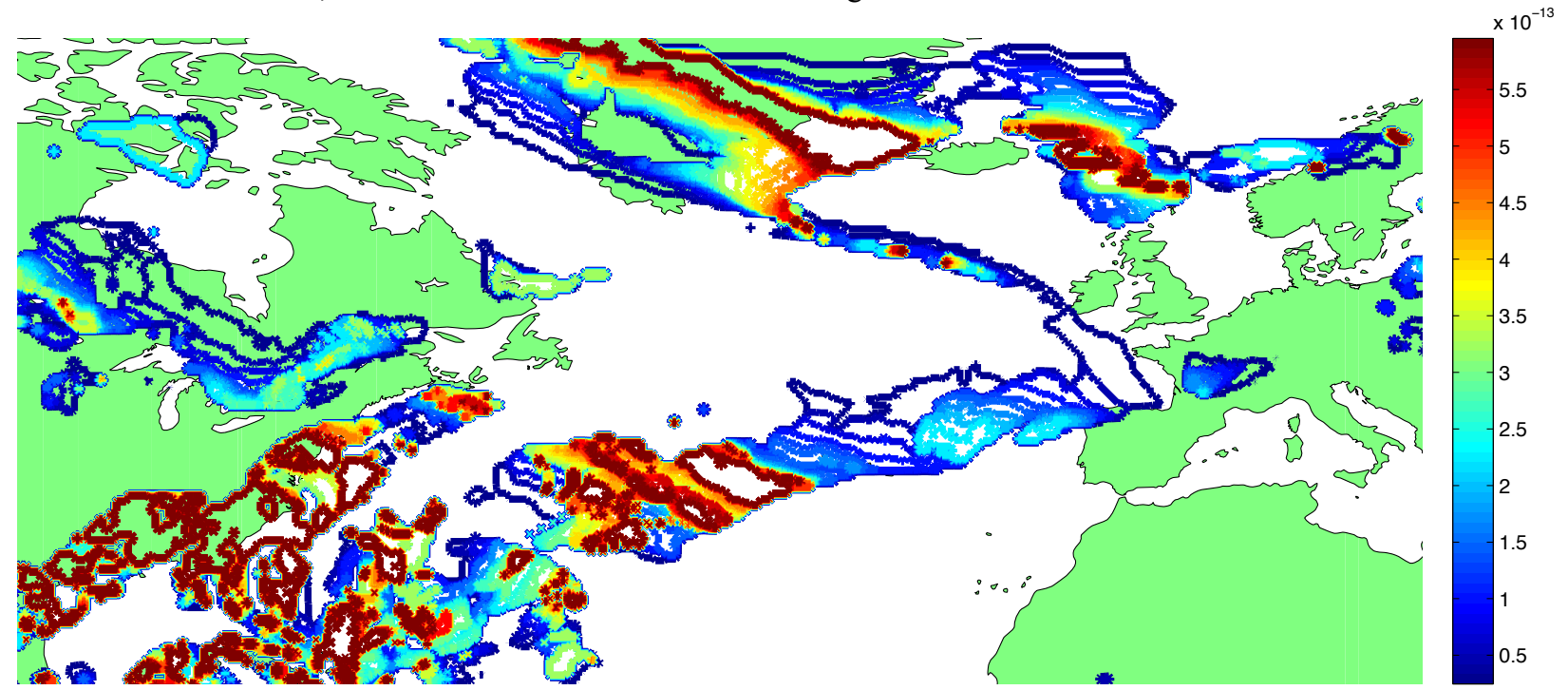

Figure 1. The potential temperature change due to contrails on 36,000 feet at 6 a.m. EDT on July 122012.

\section{Climate Optimal Trajectory Designs}

This section develops the climate-optimal trajectory algorithm for cruising aircraft by sequentially adjusting wind-optimal aircraft headings using dynamic programming techniques. The climate impact of aircraft $\mathrm{CO}_{2}$ emission and contrails is assessed by the total AGTP induced along the horizontal trajectory at multiple cruise altitudes. The climate-optimal trajectory combines a sequence of wind-optimal trajectory segments and heading adjustments that minimizes the total AGTP. The wind-optimal segments minimize aircraft fuel burn and emissions in the presence of winds while the sequential changes in wind-optimal heading and cruise altitudes account for the climate impact of contrails. 
Section III.A presents the aircraft model and dynamical equations that govern the optimal aircraft heading in winds on surface of a sphere. Section III.B presents the objective cost function and Section III.C outlines the procedures that minimize the cost.

\section{A. Wind-Optimal Trajectory Generation}

The aircraft equations of motion at a constant altitude above the spherical Earth's surface are:

$$
\begin{aligned}
& \dot{\phi}=\frac{V \cos \psi+u(\phi, \theta, h)}{R \cos \theta}, \\
& \dot{\theta}=\frac{V \sin \psi+v(\phi, \theta, h)}{R},
\end{aligned}
$$

subject to the conditions that thrust equals drag, flight path angle is zero, and the boundary constraints are met. $\phi$ is longitude and $\theta$ is latitude, $\psi$ is heading angle, and $R$ is the Earth's radius. The east-component of the wind velocity is $u(\phi, \theta, h)$, and the north-component of the wind velocity is $v(\phi, \theta, h)$. It is assumed that the Earth is a sphere and $R>>h$.

The previous study ${ }^{19}$ applies Pontryagin's Minimum Principle to determine the heading angle that is assumed to be the control available for aircraft during cruise for minimizing the cost of travel time and persistent contrail formation. When neglecting contrails, the horizontal trajectory is optimized by determining the heading angle that minimizes travel time in the presence of winds. The dynamical equation for the optimal aircraft heading ${ }^{20}$ is:

$$
\dot{\psi}=\frac{-F_{\text {wind }}(\psi, \phi, \theta, u, v, V)}{R \cos \theta},
$$

where $F_{\text {wind }}(\psi, \phi, \theta, u, v, V)$ is aircraft heading dynamics in response to winds and is expressed as:

$$
\begin{aligned}
F_{\text {wind }}(\psi, \phi, \theta, u, v, V) & \\
= & {\left[-\sin \psi \cos \psi \frac{\partial u(\phi, \theta, h)}{\partial \phi}+\cos ^{2} \psi \sin \theta u(\phi, \theta, h)+\cos ^{2} \psi \cos \theta \frac{\partial u(\phi, \theta, h)}{\partial \theta}-\frac{\partial v(\phi, \theta, h)}{\partial \phi}\right.} \\
& \left.+\sin \psi \cos \psi \sin \theta v(\phi, \theta, h)+\cos \psi \sin \psi \cos \theta \frac{\partial v(\phi, \theta, h)}{\partial \theta}+V \cos \psi \sin \theta+\cos ^{2} \psi \frac{\partial v(\phi, \theta, h)}{\partial \phi}\right] .
\end{aligned}
$$

Deriving the wind-optimal dynamical equation reduced the trajectory optimization problem from a two-point boundary value problem ${ }^{20}$ to an initial value problem. Numerical algorithms such as collocation methods or interpolation techniques can be applied to determine the optimal initial aircraft heading. In the case that an aircraft cruises at a single altitude, the minimum-time trajectory is completely specified by integrating Eqs. (4-7) simultaneously from the origin to the destination using the optimal initial aircraft heading. Note that the minimumtime trajectory is fuel-optimal for aircraft cruise at a constant altitude.

\section{B. Climate Cost Function}

The past study ${ }^{19}$ minimizes the climate impact for several types of aircraft emissions and total contrail formation time for aircraft cruise at a single altitude. The cost function used in that study penalized travelling time, climate impact of aircraft emissions in terms of GWP, and flying through penalty areas. The climate impact of aircraft emissions and contrails is modeled separately since GWP for contrails is not available in the literature. The locations of airspace favorable to persistent contrail formation modeled as regions to be avoided by aircraft by imposing a soft penalty for going through these regions. The climate impact of contrails is assumed to be uniform inside the penalty regions without considering the size of contrail area and its lifetime. ${ }^{19}$ The impact of contrails on climate is simplified by assessing the total aircraft travel time inside the regions.

This study develops the optimization algorithm based on a common climate metric for assessing the total environmental impact of aircraft flying at several cruising altitudes. The climate-optimal trajectory minimizes total 
AGTP over a selected time horizon due to aircraft emissions and contrails. The total climate cost for a particular time in the future, $H$, is defined as:

$$
J(H)=\int_{t_{0}}^{t_{f}}\left[\sum_{i} C_{i} \cdot A G T P_{i}(H, \phi, \theta, h) \cdot E I_{i} \cdot f(m, h)+C_{r} A G T P^{\text {Contrails }}(H, \phi, \theta, h)\right] d t,
$$

where $C_{i}$ is the cost coefficient of emission $i, A G T P_{i}$ and $E I_{i}$ is the AGTP and the Emission Index of trace gas $i$, respectively, $\mathrm{C}_{\mathrm{r}}$ is the cost coefficient of contrails, and $A G T P^{\text {contrails }}$ is the contrail induced AGTP. In general, the climate impact, in terms of AGTP, contributed by aircraft emissions and contrails varies with geographical location and ending time horizon.

Without loss of generality, this current optimization adapts a cost function that includes only aircraft $\mathrm{CO}_{2}$ emission and contrails. The climate impact of $\mathrm{CO}_{2}$ is assumed to be independent of the emission locations. Climate impact of contrails depends on the atmospheric conditions that vary with geographic location and changes over time. The cost objective is rewritten as:

$$
J(H)=\int_{t_{0}}^{t_{f}}\left[A G T P^{C O_{2}}(H) \cdot E I_{i} \cdot f(m, h)+A G T P^{\text {Contrails }}(H, \phi, \theta, h)\right] d t
$$

Note that the optimization algorithm discussed in the next subsection remains unchanged when the new cost function is used.

\section{Three-Dimensional Climate-Optimal Trajectory Design}

This study integrates the technique of aircraft wind-optimal heading and the concept of Dynamic Programming (DP) to generate the climate-optimal trajectories.. The optimal aircraft turning and step climbing and descending locations are optimized based on the climate cost-to-go associated with each extremal generated by forward or backward integrations using the dynamical equations for optimal heading and aircraft motion from various points in the airspace. The values of climate cost-to-go at various points in the airspace are computed using Eq. (9) along each extremals.

Assuming that there are N-1 possible turns that each includes an adjustment in the aircraft heading with or without altitude change and $\mathrm{n}$ possible locations for each turn, a forward dynamic programming approach with $\mathrm{N}-1$ stages and $n$ possible states in the set of $S_{N}$ for each stage can be formulated as:

$$
\begin{aligned}
& J\left(S_{N}\right)=0 \\
& J\left(S_{N-1}\right)=\min _{S_{N-1}}\left\{J\left(S_{N}\right)+C_{N-1}\left(S_{N-1}\right)\right\} \\
& J\left(S_{N-2}\right)=\min _{S_{N-2}}\left\{J\left(S_{N-1}\right)+C_{N-2}\left(S_{N-2}\right)\right\} \\
& \vdots \\
& J\left(S_{1}\right)=\min _{S_{1}}\left\{J\left(S_{2}\right)+C_{1}\left(S_{1}\right)\right\} \\
& J\left(S_{0}\right)=\min _{S_{0}}\left\{J\left(S_{1}\right)+C_{0}\left(S_{0}\right)\right\}
\end{aligned}
$$

Note that, the starting cost at the origin $J\left(S_{N}\right)$ is zero with $\mathrm{N}$ stages to go. The optimal cost-to-go at the N-1 stage, $J\left(S_{N-1}\right)$, is the link cost, $\mathrm{C}_{\mathrm{N}-1}\left(\mathrm{~S}_{\mathrm{N}-1}\right)$, from the origin to the current state. The link cost is specified by Eq. (9) along the wind-optimal flight path. In general, the optimal cost-to-go at any arbitrary stage depends on the optimal cost-to-go in the previous stage and the minimum cost from previous stage to the current stage. The optimal cost is repeatedly solved until the destination is reached at $\mathrm{S}_{0}$. The optimal solution can be found in $\mathrm{O}((\mathrm{N}-1) \times \mathrm{n} \times \mathrm{n})$ operations. Each operation involves computation of the link cost and determining the optimal cost-to-go. The computation time for this approach is very high since the optimal solution at each state has to be computed to provide the final solution.

The following algorithm approximates the aforementioned approach by solving N-1 individual DP problems that each has one turn $(\mathrm{N}=2)$ in order to reduce the computational effort. Each of the 1-stage DP problem can be written as the following: 


$$
\begin{aligned}
J\left(S_{2}\right) & =0 \\
J\left(S_{1}\right) & =\min _{S_{1}}\left\{J\left(S_{2}\right)+C_{1}\left(S_{1}\right)\right\} \\
J\left(S_{0}\right) & =\min _{S_{0}}\left\{J\left(S_{1}\right)+C_{0}\left(S_{0}\right)\right\} \\
\Rightarrow J\left(S_{0}\right) & =\min _{S_{1}}\left\{C_{1}\left(S_{1}\right)+C_{0}\left(S_{0}\right)\right\}
\end{aligned}
$$

The solution for each problem is the optimal aircraft turning location that becomes the origin for the subsequent problems. Note that the final destination is the same for each simplified problem and because of that the complexity of this algorithm is reduced to $\mathrm{O}(\mathrm{N} \mathrm{x} \mathrm{n})$. This algorithm when applied in the real time also accommodates the frequently updated weather forecast and dynamic nature of atmospheric conditions by optimizing the aircraft trajectory segments at each turning location using most updated weather forecast. The following five steps compute the climate-optimal trajectory during cruise.

1. Using a range of different initial heading angles at the initial position, a collection of wind-optimal extremals is generated by forward integrating Eqs. (4-7) until ending time of the period allowed for adjusting altitude and/or aircraft heading. Applying Eq. (9) for the extremals to provide the minimum climate cost-to-go, $C_{I}\left(S_{1}\right)$, from the origin to any points along them. Note that the time location for adjusting altitude and/or aircraft heading can be optimized within the period of forward integration. It can also be pre-determined to accommodate operational requirements.

2. Using a range of different final heading angles at the destination, another collection of wind-optimal extremals is generated by backward integrating Eqs. (4-7) at all selected cruise altitudes. This is done for a fixed period of time, estimated based on the difference between the total travel time and the aircraft turning time. Applying Eq. (9) for the extremals to provide the minimum climate cost-to-go, $C_{0}\left(S_{0}\right)$, to the destination from any points along them.

3. Delaunay triangulation and interpolation techniques can be applied to estimate the climate cost-to-go from any point in the covered airspace region using the points on the extremals. Identify the optimal aircraft turning location, $S_{I}$ that has the minimum climate cost-to-go at the aircraft turning time (i.e. the end of the forward extremals). It is assumed that the step climb or descent is instantaneous.

4. After determining the optimal turning location, repeat step 1 to step 3 at the new starting position.

5. When the last turning location is reached, the climate optimal trajectory segment from the last turning location to the final destination is calculated by forward integrating Eqs. (4-7) using the correct heading angle that is calculated by interpolating the aircraft heading from the backward extremals at step 2.

\section{Results}

This section generates the climate-optimal trajectories for flights crossing North Atlantic Tracks (NAT). NAT are trans-Atlantic routes across the busiest oceanic airspace in the world. Current air traffic control requires a higher aircraft separation standard in the oceanic region due to limited radar surveillance. The airspace is congested at peak hours because of the large horizontal separation criteria and a narrow range of fuel-efficient flight levels. A system of tracks known as the Organized Track System (OTS) is constructed to increase the throughput of trans-Atlantic air traffic system by aligning the air traffic flows with their minimum time tracks and altitude profiles. Eastbound and westbound minimum time tracks are seldom identical in the presence of jet streams. Separate organized track structure is therefore created and published daily for each of the major flows. This section evaluates the potential cost and benefits of flying climate-optimal routes across NAT and their impacts to OTS.

The wind-optimal and climate-optimal trajectories are generated for a day, July 12, 2012, that has atmospheric conditions highly favorable to persistent contrail formation. Each climate-optimal trajectory minimizes the total climate cost as defined in Eq. (9). Each wind-optimal trajectory is calculated using Eq. (9) when neglecting $\mathrm{CO}_{2}$ emissions; and it is fuel minimal. The results are used to assess the potential climate benefits, associated costs and the impact to NAT structure. In this study, each flight is allowed to perform en-route step climbs or descents while adjusting wind-optimal headings every 60 minutes sequentially for fuel conservation or contrail mitigation until the destination is reached. The optimal aircraft turning locations and the trajectory segments are solved as shown in Section III.

The flight schedules and aircraft data for trans-Atlantic air traffic during the day are provided by FAA's Enhanced Traffic Management System (ETMS). A total of 960 trans-Atlantic flights are selected for this study. There are 482 eastbound and 478 westbound flights for this day. The top five airport pairs are listed in Table 3 for the eastbound and westbound flights that constitute almost $12 \%$ of the entire transatlantic fleet for the day. In this 
paper, Eurocontrol's Base of Aircraft Data Revision 3.6 (BADA) ${ }^{21}$ provides the fuel consumption model. The emission model is based on the FAA's Aviation Environmental Design Tool (AEDT) ${ }^{22}$. Climate impact due to $\mathrm{CO}_{2}$ emission and contrails for these trajectories are based on the climate models discussed in Section II.

Table 3. Top 5 city pairs for the trans-Atlantic flights.

\begin{tabular}{|l|l|l|l|}
\hline Eastbound & Total Flights & Westbound & Total Flights \\
\hline New York (KJFK) - London (EGLL) & 20 & London (EGLL) - New York (KJFK) & 20 \\
\hline New York (KJFK) - Paris (LFPG) & 11 & Paris (LFPG) - New York (KJFK) & 10 \\
\hline Newark (KEWR) - London (EGLL) & 10 & London (EGLL) - Newark (KEWR) & 10 \\
\hline Chicago (KORD) - London (EGLL) & 10 & London (EGLL) - Chicago (KORD) & 10 \\
\hline Los Angeles (KLAX) - London (EGLL) & 8 & Frankfurt (EDDF) - Chicago (KORD) & 8 \\
\hline
\end{tabular}

\section{A. Climate-optimal and Wind-optimal Trajectories from New York to London}

A climate-optimal trajectory is compared to its wind-optimal counterpart for a trans-Atlantic flight from New York to London with respect to the variation of the route structure and also in terms of AGTP reduction, additional fuel burn and travel time. The climate-optimal trajectory is generated for fulfilling a climate optimal goal, Opt25, which is aimed at minimizing the total AGTP due to aircraft $\mathrm{CO}_{2}$ emission and contrails at the end of 25 years. It is generated by applying the algorithm discussed in Section IIIC and using weather data from GFS. The wind-optimal trajectory that is equivalent to a minimum-time route on a horizontal plane is fuel-optimal along the vertical profile. Note that current NAT structure is constructed based on wind-optimal routes.

Figure 2 shows the horizontal wind-optimal trajectory in a black-solid line for an eastbound flight from New York to London. The climate-optimal trajectory for opt 25 is depicted in a dash-dotted line. The various colored polygons represent the AGTP values in kelvin for a 25 years horizon contributed per kilometer of contrail formation at the corresponding location in the region. In this example, the climate-optimal trajectory located at a higher latitude avoided traversing the airspace favorable to severe contrail formation near the origin and is close to the wind-optimal trajectory near the destination. Figure 3 shows the vertical profile for the wind-optimal trajectory in a black-solid line and the climate-optimal trajectory in a blue-dash-dotted line, respectively. In additional to the horizontal maneuver, this flight reduced potential contrails formation by flying a lower cruise altitude in early stage and gradually step-climbed to a higher altitude for fuel savings. For this particular flight, the climate-optimal trajectory reduced potentially $86 \%$ of total AGTP value at the end of 25 year horizon with an additional $2.2 \%$ fuel burn and $6.4 \%$ travel time when compared to the wind-optimal trajectory.

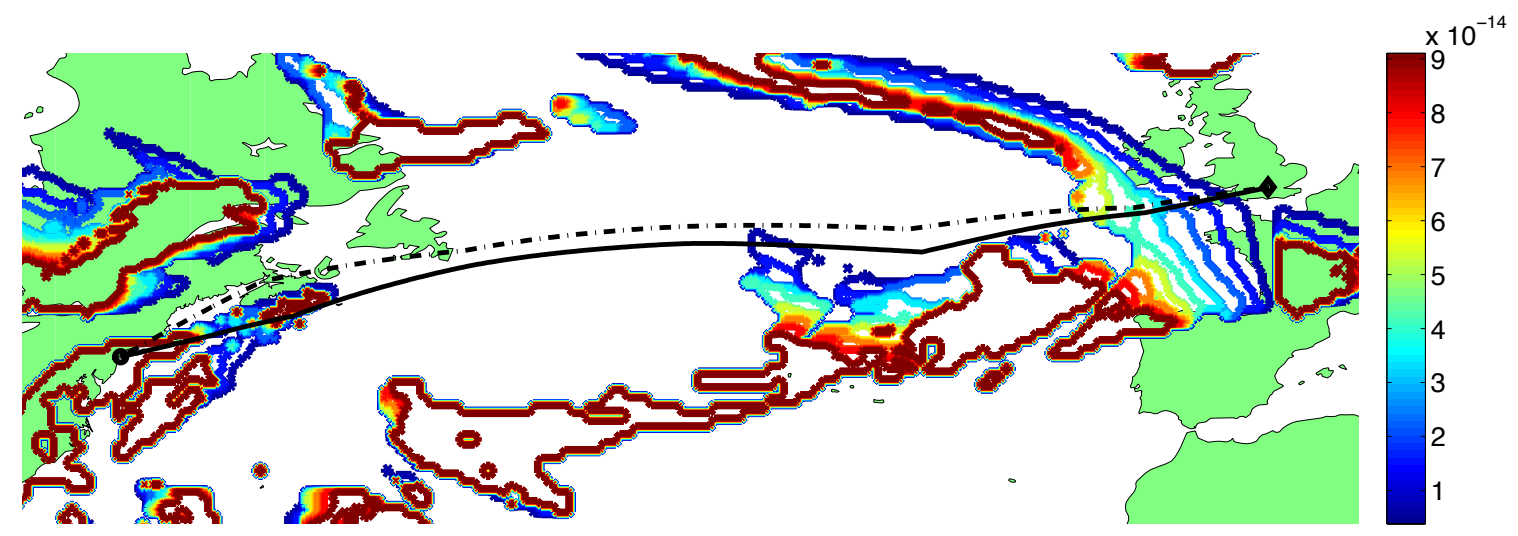

Figure 2. Horizontal trajectories for a trans-Atlantic flight from New York to London at 35,000 feet. Climate-optimal trajectory is the blue-dash-dotted and wind-optimal is solid.

\section{B. Climate Benefits and Costs for the Trans-Atlantic Flights}

The evaluation in the previous subsection is extended to the entire fleet for the day. The AGTP values at the end of 25 years of the climate-optimal trajectories for Opt25 are compared to those of the wind-optimal trajectories for all of the trans-Atlantic flights. The eastbound and westbound flights are grouped separately and binned according to the percentage of AGTP reduction. The distributions are shown in Fig. 4 where the bin centers are shown on $\mathrm{x}-$ axis. The distributions are not uniform or normal. A large portion of westbound flights has less than $15 \%$ AGTP reduction while almost the same portion of eastbound flights has more than $75 \%$ AGTP reduction. This is because 


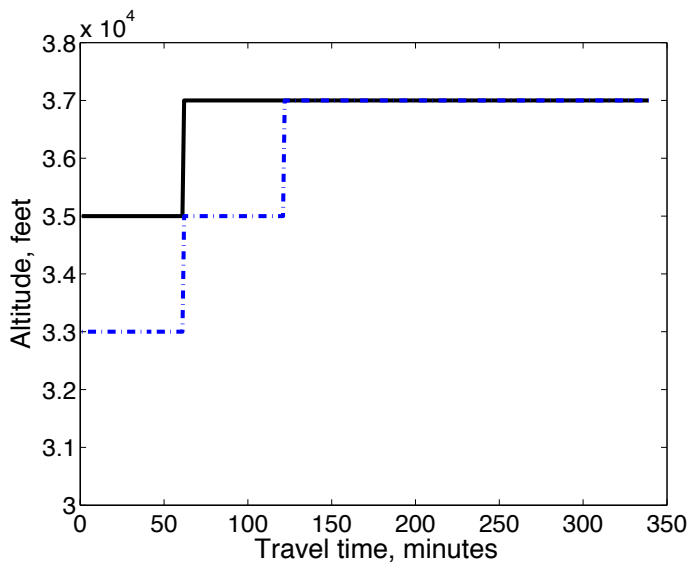

Figure 3. Vertical profiles for the trans-Atlantic flight. Climate-optimal trajectory is the blue-dash-dotted and wind-optimal is solid.

westbound flights operate in strong headwinds while eastbound flights encounter strong tailwinds. Westbound flights that avoid traversing contrails favorable regions by perturbing away from their wind-optimal profiles consume more additional fuel and produce more aircraft emissions in the presence of strong head winds. It is more effective for eastbound flights to reduce climate impact of contrails since they can fly a longer distance with relatively less fuel burn in the presence of strong tail winds. Sometimes, the climate-optimal trajectory that minimizes total climate impact due to aircraft emissions and contrails is equivalent to the wind-optimal trajectory when climate impact of addition emissions exceeds those of contrails at the end of predetermined time horizon. Nonetheless, the potential impact of contrails to the eastbound and westbound flights is different and varies with geographical locations and time. Current study can be modified using traffic and weather data for extended periods of time to get a better understanding of the effectiveness of the climate-optimal trajectories.

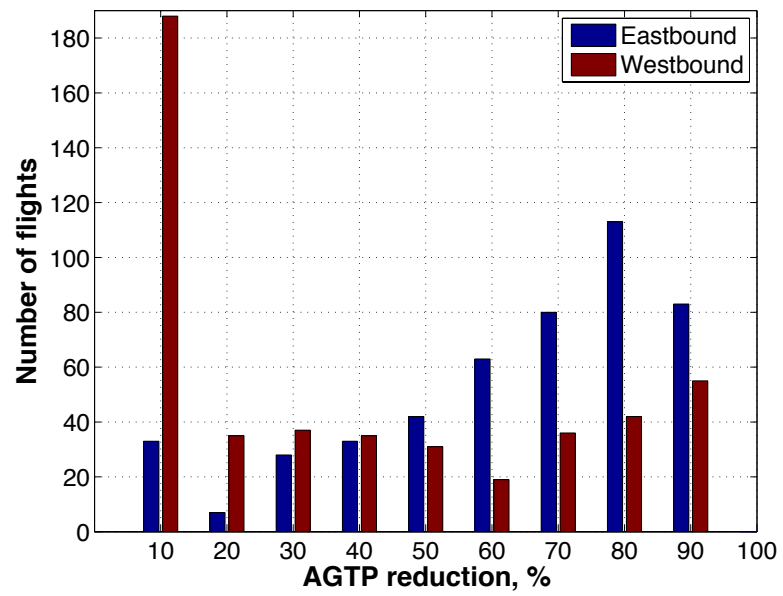

Figure 4. Climate impact reduction for the trans-Atlantic fligthts on July 12, 2012.

The bar graphs in Fig. 5 show the additional fuel burn and travel time when compared to the wind-optimal trajectories. About $50 \%$ of eastbound and westbound flights consume less than $3 \%$ of additional fuel, and almost all the flights burns less than $20 \%$ of additional fuel for Opt 25 . Note that actual amount of fuel burn for westbound flight is larger due to a higher fuel consumption for the wind-optimal baseline in strong headwinds. The additional travel time is not necessary positive since the wind-optimal trajectories are fuel-minimal and not time-minimal. Almost all flights arrive at the destination within $10 \%$ of original arrival time.

The performances of the climate-optimal trajectories are summarized in Table 4. Similar to Opt25, two more climate-optimal goals, Opt50, Opt100, each minimizes the climate impact at the end of 50 and 100 years, respectively, are also considered in this study. These climate-optimal goals aimed at minimizing the short, medium and long-term aviation induced climate impacts for trans-Atlantic air traffic. Three values of $\mathrm{RF}_{\text {net }}$ are chosen to investigate the impact of uncertainty in contrail radiative forcing on the climate goals. The mean of AGTP reduction 

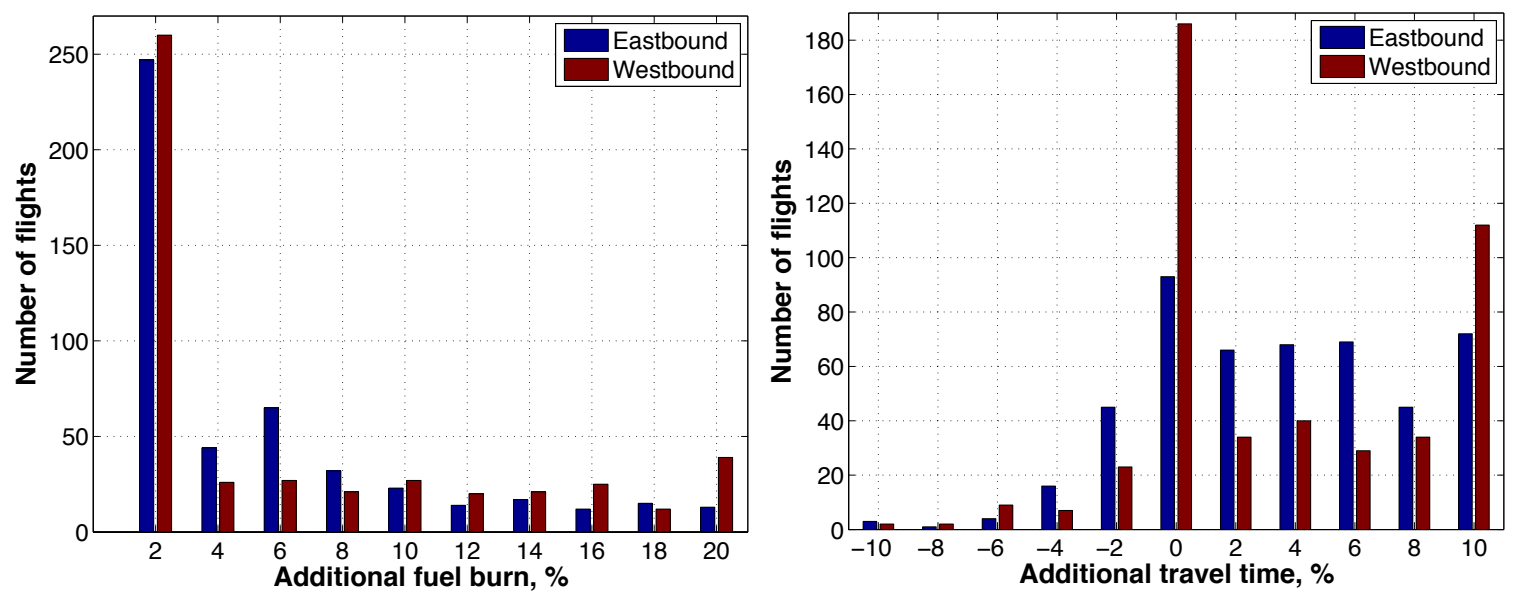

Figure 5. The additional fuel burn and travel time for climate impact reduction.

at the end of the targeted year for the entire fleet and associated additional fuel burn and travel time for each goals and radiative forcing are provided in Table 4. The AGTP reduction is larger and the additional fuel burn is smaller for the eastbound flights in all cases. In case of a medium-term climate goal, Opt50 and a nominal contrails $\mathrm{RF}_{\text {net, }}$, $10 \mathrm{~W} / \mathrm{m}^{2}$, the total AGTP reduction is $38 \%$ with additional $3.1 \%$ fuel burn and $3.1 \%$ travel time for the eastbound flights and 20\% AGTP reduction with additional 3.7\% fuel burn and 3.0\% travel time for the westbound flights. The AGTP reduction increases when a shorter-term climate goal is adopted or a larger contrail radiative forcing is assumed because contrails have a short-term climate impact.

Table 4. AGTP reduction, additional fuel burn and travel time for the climate-optimal strategies.

\begin{tabular}{|c|l|c|c|c|c|c|c|c|c|c|}
\hline \multicolumn{2}{|c|}{$\mathrm{RF}_{\text {net }}\left(\mathrm{W} / \mathrm{m}^{2}\right)$} & \multicolumn{3}{|c|}{ Opt25 } & \multicolumn{3}{c|}{ Opt50 } & \multicolumn{3}{c|}{ Opt100 } \\
\cline { 3 - 11 } \multicolumn{2}{|c|}{} & $\begin{array}{c}\text { AGTP } \\
(\%)\end{array}$ & $\begin{array}{c}\text { Fuel } \\
(\%)\end{array}$ & $\begin{array}{c}\text { Time } \\
(\%)\end{array}$ & $\begin{array}{c}\text { AGTP } \\
(\%)\end{array}$ & $\begin{array}{c}\text { Fuel } \\
(\%)\end{array}$ & $\begin{array}{c}\text { Time } \\
(\%)\end{array}$ & $\begin{array}{c}\text { AGTP } \\
(\%)\end{array}$ & $\begin{array}{c}\text { Fuel } \\
(\%)\end{array}$ & $\begin{array}{c}\text { Time } \\
(\%)\end{array}$ \\
\hline \multirow{2}{*}{3.3} & Eastbound & -42 & 3.3 & 3.1 & -19 & 2.2 & 2.4 & -17 & 2.1 & 2.4 \\
\cline { 2 - 11 } & Westbound & -22 & 4.1 & 3.1 & -10 & 2.3 & 1.7 & -9 & 2.1 & 1.3 \\
\hline \multirow{2}{*}{10} & Eastbound & -63 & 4.5 & 3.8 & -38 & 3.1 & 3.1 & -35 & 2.9 & 3.0 \\
\cline { 2 - 11 } & Westbound & -36 & 5.5 & 4.4 & -20 & 3.7 & 3.0 & -18 & 3.5 & 2.8 \\
\hline \multirow{3}{*}{30} & Eastbound & -79 & 5.8 & 4.5 & -59 & 4.2 & 3.7 & -56 & 4.1 & 3.6 \\
\cline { 2 - 10 } & Westbound & -48 & 6.6 & 5.7 & -33 & 5.3 & 4.2 & -31 & 5.0 & 4.0 \\
\hline
\end{tabular}

\section{Potential Change in NAT due to a Climate-optimal Goal}

The potential changes in NAT air traffic patterns are investigated for eastbound and westbound flights based on the climate-optimal trajectories designed for Opt25. The vertical and horizontal aircraft profiles of the climateoptimal trajectories are compared to that of wind-optimal trajectories for each flight. The difference in cruise altitudes for each flight between the two trajectories is recorded from start until the end of the shorter trajectory. Note that the two trajectories can have different travel times. The aggregated results for the entire fleet are presented in Fig.6(a). The percentages of times when the altitudes are above or below the wind-optimal cruise altitudes are shown for the eastbound and westbound flights separately. The optimal cruise altitudes remain the same in almost $60 \%$ of time for the entire fleet for both traffic directions. The entire fleet fly longer in time at lower altitudes for the $40 \%$ remaining time i.e., $28 \%$ for the eastbound flights and 30\% for the westbound flights. This result is consistent with the past findings that contrail formation is less severe at lower cruise altitudes. In addition, the altitude range of westbound flights is more varied. This implies that reducing potential contrail formation by changing cruise altitudes is more frequently adapted for westbound flights since horizontal maneuver costs more fuel burn in the presence of strong head winds. Furthermore, both eastbound and westbound flights cruise above and below the original altitudes. Therefore, the range of climate-optimal altitudes is larger than the range of fuel-efficient altitudes.

The horizontal aircraft profiles of the climate-optimal trajectory and wind-optimal trajectory are investigated with respect to the latitude changes. Note that trans-Atlantic air traffic is separated into major eastbound and westbound flow and in general westbound traffic was located at a higher latitude when flying wind-optimized routes. The latitude difference for each flight between the two types of trajectories is recorded and the aggregated 
results for the entire fleet are presented in Fig.6(b). The latitude differences are small for almost $45 \%$ of time for the entire fleet for both traffic directions. However, major eastbound traffic spends $37 \%$ of time at a higher latitude that leans toward the north while the westbound traffic spends $32 \%$ time at lower latitudes that lean toward the south. This brings the two major flows closer in latitude direction.
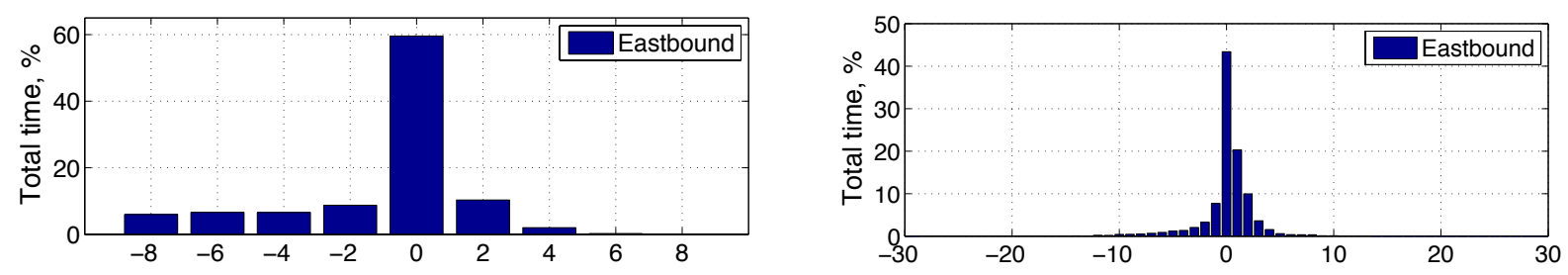

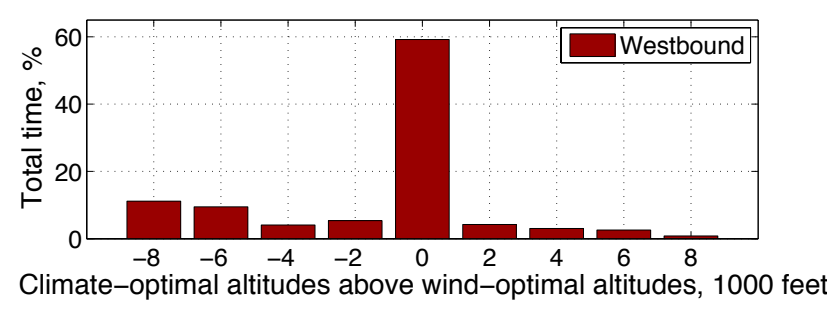

(a)

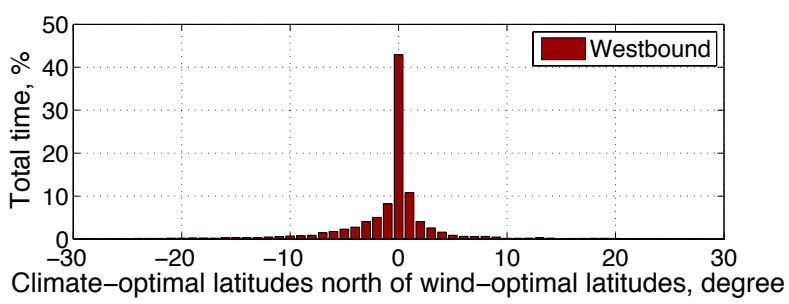

(b)

Figure 6. Difference in cruise altitudes (a) and latitude (b) between the two sets of optimal trajectories.

\section{Conclusion}

A three-dimensional trajectory optimization algorithm capable of minimizing the climate impact of aircraft $\mathrm{CO}_{2}$ emissions and contrails was developed in this study. The optimization capability integrated an air traffic management simulation with aircraft fuel burn and emissions models, contrail formation and dispersion models, simplified climate response models, and a common climate metric to evaluate the potential cost and benefits of flying climate-optimal routes in the North Atlantic. The climate-optimal trajectories aimed at minimizing the short, medium and long term aviation induced climate impact were compared to the wind-optimal trajectories for the eastbound and westbound NAT air traffic flows in terms of temperature change reduction, additional fuel burn and travel time, and variation of route structure. Eastbound flights achieved a higher temperature change reduction with less additional fuel burn than westbound flights that operated in strong headwinds that caused more additional fuel burn and aircraft emissions to avoid traversing contrails favorable regions. For a medium-term climate goal and a nominal contrails radiative forcing, the total AGTP reduction is $38 \%$ with additional $3.1 \%$ fuel burn and $3.1 \%$ travel time for the eastbound flights and 20\% AGTP reduction with additional 3.7\% fuel burn and $3.0 \%$ travel time for the westbound flights. The AGTP reduction increases when a shorter-term climate goal is adopted or a larger contrail radiative forcing is assumed because contrails have a short-term climate impact. The range of climate-optimal altitudes was wider than the range of fuel-efficient altitudes. The latitude differences were small between climateoptimal and the wind-optimal trajectories for almost $45 \%$ of time but the major eastbound traffic leaned forward to the north while the westbound traffic to the south for the rest of the time.

The results in this study were based on the trans-Atlantic air traffic during a day, July 12, 2012. The results can be modified using the traffic and weather data for extended periods of time to get a better understanding of the relation between climate benefits and additional cost and the potential impact to the NAT structure.

\section{References}

${ }^{1}$ Brasseur, G. P. and Gupta, M., "Impact of Aviation on Climate: Research Priorities," Bull. Amer. Meteor. Soc., Vol. 91, 461-463, April 2010.

${ }^{2}$ Boucher O., "Atmospheric science: Seeing through contrails," Nature Climate Change, 1, 24-25, 2011.

${ }^{3}$ Klima, K., "Assessment of a Global Contrail Modeling Method and Operational Strategies for Contrail Mitigation," M.S. Thesis, MIT, 2005.

${ }^{4}$ Sridhar, B., Chen, N. Y., and Ng, H. K., "Fuel Efficient Strategies for Reducing Contrail Formations in United State National Air Space," 29th Digital Avionics Systems Conference, Salt Lake City, UT, October 2010.

${ }^{5}$ Sridhar, B., Ng, H. K., Chen, N. Y., "Aircraft Trajectory Optimization and Contrail Avoidance in the Presence of Winds," AIAA Aviation Technology, Integration, and Operation Conference, September 2010, Fort Worth, TX. 
${ }^{6}$ Campbell, S. E., Neogi, N. A., and Bragg, M. B., “An Optimal Strategy for Persistent Contrail Avoidance,” AIAA 20086515, AIAA Guidance, Navigation, and Control Conference, Honolulu, Hawaii, 2008.

${ }^{7}$ Fuglestvedt, J. S., Shine, K. P., Berntsen, T., Cook, J., Lee, D. S., Stenke, A., Skeie, R. B., Veldes, G. J. M., ad Waitz, I. A., "Transport impacts on Atmosphere and Climate: Metrics," Atmosphere Environment, Vol. 44, No. 37, 2010, pp. 4648-4677, doi:10.1016/j.atmosenv.2009.04.044.

${ }^{8}$ Khodayari, A., Wuebbles D. J., Olsen, S., Fuglestvedt, J.S., Berntsen, T., Lund, M. T., Waitz, I., Wolfe, P., and Forster, P., "Intercomparision and evaluation of the capabilities of simple climate models to project the effects of aviation on climate," WCRP Conference, October 2011.

${ }^{9}$ Aviation environmental Portfolio Management Tool, Partnership for AiR Transportation Noise \& Emissions reduction, http://web.mit.edu/aroastro/partner/apmt.

${ }^{10}$ Sridhar, B., Ng, H. K., and Chen, N. Y., "Integration of Linear Dynamic Emission and Climate Models with Air Traffic Simulations," AIAA Guidance, Navigation and Control Conference, Minneapolis, MN, 2012.

${ }^{11} \mathrm{Li}$, Jinhua, Caiazzo, F., Chen, N., Sridhar, B., and Ng, H., "Access Aircraft Contrails using Dynamic Contrail Model," AIAA Guidance, Navigation and Control Conference, Boston, MA, 2013.

${ }^{12}$ Shine, K. P., Fuglestvedt, J. S., Hailemariam, K., Stuber, N., 2005b. "Alternatives to the global warming potential for comparing climate impacts of emissions of greenhouse gases," Climatic Change 68, 281-302.

${ }^{13}$ Forster, P., Ramaswamy, V., Artaxo, P., Berntsen, T., Betts, R., Fahey, D.W., Haywood, J., Lean, J., Lowe, D.C., Myhre, G., Nganga, J., Prinn, R., Raga, G., Schulz, M., Van Dorland, R., 2007a. Changes in atmospheric constituents and in radiative forcing. In: Solomon, S., et al. (Eds.), Climate Change 2007: the Physical Science Basis. Contribution of Working Group I to the Fourth Assessment Report of the Intergovernmental Panel on Climate Change. Cambridge University Press, Cambridge.

${ }^{14}$ Hartmann, D. L., Global Physical Climatology, Academic Press, San Diego, CA, 1994.

${ }^{15}$ Boucher, O. and Reddy, M. S., "Climate trade-off between black carbon and carbon dioxide emissions," Energy Policy, 36, pp 193-200, 2008.

${ }^{16}$ Meerkötter, R., Schumann, U., Minnis, P., Doelling, D. R., Nakajima, T., and Tsushima, Y. "Radiative Forcing by Contrails," Ann. Geophysicae, Vol. 17, 1999, pp. 1080-1094, doi: 10.1007/s00585-999-1080-7.

${ }^{17}$ Haywood, J. M., Allan, R. P., Bornemann, J., Forster, P. M., Francis, P. N., Milton, S., Rädel, G., Rap, A., Shine, K. P., and Thorpe, R., "A Case Study of the Radiative Forcing of Persistent Contrails Evolving into Contrail-Induced Cirrus," Journal of Geophysical Research, Vol. 114, D24201, doi:10.1029/2009JD012650, 2009.

${ }^{18}$ Schumann, U., Graf, K., and Mannstein, H., "Potential to Reduce the Climate Impact of Aviation by Flight Level Changes," 3rd AIAA Atmosphere Space Environments Conference, AIAA Paper 2011-3376, Honolulu, Hawaii, 2011.

${ }^{19} \mathrm{Ng}$, H. K., Sridhar, B., Grabbe, S., and Chen, N., "Cross-Polar Aircraft Trajectory Optimization and the Potential Climate Impact," IEEE/AIAA 30 ${ }^{\text {th }}$ Digital Avionics Systems Conference, Oct. 2011.

${ }^{20}$ Bryson, A. E., and Ho, Y. C., Applied Optimal Control, Taylor and Francis, Levittown, PA, 1975.

${ }^{21}$ "User Manual for the Base of Aircraft Data (BADA), Revision 3.6," Eurocontrol Experimental Center (EEC) Note No. 10/04, Project ACE-C-E2, Sept. 2004.

${ }^{22}$ Federal Aviation Administration, Washington, DC, Aviation Environmental Design Tool (AEDT) User Guide: Beta1c, October 2010. 